\title{
Colonialidade e o marco temporal da ocupação de terras indígenas: uma crítica à posição do Supremo Tribunal Federal
}

\author{
Coloniality and the temporal framework of indigenous lands \\ occupation: a critique of the position of the Brazilian Supreme Court
}

\author{
Dailor Sartori Junior
}

\begin{abstract}
Resumo
No julgamento da Petição 3.388 pelo Supremo Tribunal Federal, em 2009, além da confirmação da constitucionalidade da demarcação da Terra Indígena Raposa Serra do Sol, criou-se a tese do "marco temporal da ocupação", a qual afirma que o direito a uma terra indígena só deve ser reconhecido quando a área se encontrava tradicionalmente ocupada na promulgação da Constituição, 05 de outubro de 1988, a menos que se comprove o "renitente esbulho", ou seja, a reivindicação de retorno em caso de expulsão da área. Desde então, esta tese foi aplicada pelo STF nos processos judiciais que anularam a demarcação de algumas terras indígenas. Para análise destes casos, adota-se o pensamento descolonial como referencial teórico. Assim, o artigo busca responder quais são os elementos de colonialidade presentes na fundamentação da tese do marco temporal pelo STF. Identificou-se que o marco temporal expressa a colonialidade do ser, do saber e do poder, por conta de sua anti-historicidade e desconsideração da situação de violência e tutela do passado, da imposição de formas civilistas e eurocêntricas de relação com o território e com o Estado e da legitimação do contexto político de disparidade de poder em que tais conflitos são instaurados.
\end{abstract}

Palavra-chave: Colonialidade. Marco temporal da ocupação. Terras indígenas. Supremo Tribunal Federal.

\begin{abstract}
In the judgement of the Petition 3.388 by the Brazilian Supreme Court in 2009, besides the confirmation of the constitutionality of the demarcation of the Raposa Serra do Sol Indigenous Land, the thesis of the "temporal framework of the occupation" was created, which states that the right to an indigenous land should only be recognized when the area was traditionally occupied on the date the Constitution was promulgated, October 5, 1988, unless the "reluctant trespass" is proven, that is, the claim of return in case of eviction of the area. Since then, this thesis has been applied by the STF in the lawsuits that nullified the demarcation of some indigenous lands. For the analysis of these cases, decolonial thinking is adopted as a theoretical reference. Therefore, the article aims to answer which are the elements of coloniality present in the justification of the thesis of the "temporal fra-
\end{abstract}




\begin{abstract}
mework of the occupation" of indigenous lands by the Brazilian Supreme Court. It was identified that the temporal framework expresses the coloniality of being, knowledge and power, due to its anti-historicity and disregard of the situation of violence and tutelage of the past, the imposition of civilist and Eurocentric forms of relation with the territory and with the State and the legitimation of the political context of disparity of power in which such conflicts are established.
\end{abstract}

Keywords: Coloniality. Temporal Framework of occupation. Indigenous lands. Brazilian Supreme Court.

\section{Introdução}

O julgamento da Petição 3.388 pelo Supremo Tribunal Federal (STF), no ano de 2009, que questionava a demarcação da Terra Indígena Raposa Serra do Sol, em Roraima, pode ser considerado o mais recente marco de reavaliação dos direitos indígenas desde a Constituição Federal de 1988, pois, ao confirmar a demarcação contínua de uma grande área e afastar argumentos contrários, o STF reconheceu a pluralidade cultural e a superação das políticas integracionistas que marcaram o indigenismo recente.

Entretanto, sem discussão com a sociedade, com as partes do processo ou com os povos indígenas, os Ministros consolidaram a ideia do "marco temporal da ocupação". A tese afirma que o direito a uma terra indígena só deve ser reconhecido nos casos em que a área se encontrava tradicionalmente ocupada na data da promulgação da Constituição, 5 de outubro de 1988, a menos que se comprove que a comunidade indígena tenha sido expulsa da área e nesta data estivesse reivindicando enfaticamente o seu retorno, preferencialmente por via judicial.

Depois do último recurso julgado em 2013, o marco temporal passou a ser aplicado pelo Judiciário em outras açōes movidas por proprietários de terras que questionam processos de demarcação. No STF, a Segunda Turma já anulou três demarcaçōes com base no julgamento do caso Raposa.

Se considerarmos o atual paradigma da política indigenista brasileira, que privilegia o reconhecimento das diferenças e a titularidade de direitos culturalmente específicos, sendo um giro de superação das políticas integracionistas e de tu- tela que permaneceram até a promulgação da Constituição Federal de 1988, qual o lugar simbólico desta tese jurisprudencial? É um conceito que decorre do texto constitucional ou existem circunstâncias políticas, econômicas e mesmo epistemológicas em jogo?

Para além de análises jurídicas de (in)constitucionalidade da tese, é importante se ater aos processos de estruturação das sociedades latino-americanas com passado colonial e às influências que a matriz de poder colonial inaugurada na conquista da América exerce, ainda hoje, sobre as identidades dos sujeitos coloniais, sobre a invalidação de seus saberes tradicionais e sobre a garantia do seu direito territorial (QUIJANO, 1992).

Assim, este artigo busca responder a seguinte questão: quais são os elementos de colonialidade presentes na fundamentação da tese do marco temporal da demarcação de terras indígenas pelo Supremo Tribunal Federal? Para tanto, propōem-se dois objetivos: a) analisar a afirmação do pensamento descolonial e seus conceitos-chave como categorias teóricas aptas a interpretar direitos territoriais indígenas no Brasil; e b) discutir a fundamentação da tese a partir dos casos já julgados pelo STF, considerando algumas dimensōes em que a colonialidade opera (poder, saber e ser).

\section{A colonialidade como herança da experiência colonial $e$ os projetos descoloniais}

A partir dos anos 90 , introduzindo categorias tais como gênero e raça no debate do capitalismo, Aníbal Quijano e outros pensadores latino-ame- 
ricanos ${ }^{1}$ vincularam o processo de colonização da América com a expansão mundial do sistema capitalista, ambos sendo parte do mesmo processo histórico iniciado nos séculos XV e XVI. Como consequência, um padrão de poder colonial persistia ao fim da dominação política do fenômeno do colonialismo, ao estabelecer, de forma duradoura, hierarquias étnico-raciais entre dominantes e dominados (QUIJANO, 1992, p. 14).

Este pensamento foi desenvolvimento a partir da contestação das narrativas hegemônicas e intra-europeias sobre a modernidade, que buscavam justificar a posição da Europa como centro do mundo e ápice da evolução das sociedades, bem como o saber científico e racional como paradigmas. Tais ideais são em verdade construções ideológicas possibilitadas pelo eurocentrismo, pois as populações internas e tradicionais dos países colonizados nunca usufruíram deste "legado" vendido como positivo pela racionalidade colonialista. Se o custo da modernidade enquanto discurso universal era o encobrimento de outros mundos possíveis, então haveria um lado obscuro por ser desvelado.

Assim, ao se perceber a dominação e a violência contra essas vítimas inocentes do "processo civilizador", é possível "des-cobrir", pela primeira vez, a outra face até então oculta, mas essencial da modernidade: o papel que o mundo periférico colonial, o índio assimilado, o negro escravizado, a mulher oprimida e a cultura popular silenciada desempenham na constituição da própria modernidade, enquanto vítimas de sua face irracional (DUSSEL, 2000, p. 49). Estava elaborada, então, a noção de colonialidade, que daria gênese aos estudos descoloniais posteriores.

Esta matriz persistiu com os processos de independência dos países latino-americanos, e contribuiu para a estruturação de sociedades desiguais, hierárquicas e racistas, dentro de Estados formal- mente republicanos e independentes. Através do controle político, administrativo e militar, elites brancas e proprietárias fabricaram os imaginários sociais e as memórias históricas das novas identidades nacionais. Já os povos indígenas, os negros e as populaçōes tradicionais continuaram sem espaços de poder para expressar sua cultura de forma igualitária (QUINTERO, 2010, p. 12).

Deste modo, como conceito maleável, a colonialidade opera em ao menos três níveis: a) coloca em evidência o lado obscuro da modernidade e seu papel constitutivo, não sendo possível haver modernidade sem colonialidade; b) é também a abreviação de "padrão colonial de poder" ou "matriz colonial de poder"; c) designa histórias, subjetividades, formas de vida e saberes silenciados, a partir dos quais surge a resistência descolonial (MIGNOLO, 2008, p. 9-10).

Mas se há a colonialidade, também há projetos de descolonização desta matriz de poder, através da emergência das relaçōes interculturais e da refundação do Estado para incluir outras formas de organização sociopolítica, como Bolívia e Equador pretenderam em suas constituintes emancipadoras dos anos 2000.

Neste sentido, a primeira tarefa do giro descolonial é a descolonização do conhecimento hegemônico que encobre outros saberes, o que pode ser realizado por uma atitude que Mignolo (2010) chama de "desobediência epistêmica" (MIGNOLO, 2010). Em sentido semelhante, Boaventura de Sousa Santos (2009) refere que o pensamento moderno seria um "pensamento abissal", justamente por impor uma linha divisória entre conhecimentos válidos e inválidos, que acaba por ser reproduzido nos discursos e instituiçōes jurídicas, políticas, científicas e sociais (SANTOS, 2009, p. 41).

Precisamente por buscar "uma outra racionalidade" que possibilite um intercâmbio de experiências,

${ }^{1}$ Walter Mignolo, Nelson Maldonado-Torres, Ramón Grosfoguel, Enrique Dussel, Catherine Walsh, Edgardo Lander, Arturo Escobar, Maria Lugones e Santiago Castro-Gómez sāo alguns exemplos. 
estes projetos descoloniais não visam à tomada de hegemonia do projeto moderno eurocêntrico, como se fosse a inversão dos polos da dominação. Segundo Dussel (1998), há um elemento de corporeidade que marca as vítimas da modernidade, cuja negação da vida concreta é o que motiva a se unir em projetos de resistência ao sistema capitalista global e ao paradigma da totalidade.

Desta forma, com a tomada de consciência sobre sua própria condição de vítimas e de excluídos do sistema, emergem novos sujeitos sócio-históricos, ou uma comunidade de vítimas que, a partir da ação política organizada e de uma intersubjetividade comunitária, transformam o sistema que os vitima em uma práxis de libertação (DUSSEL, 1998, p. 411).

\section{Os direitos territoriais indígenas e a emergência da territorialidade}

O caminho percorrido até o atual paradigma do reconhecimento, que irradia deveres de respeito e promoção das diferenças, foi tortuoso na história jurídico-política brasileira: desde a colonização até a promulgação da Constituição de 1988, é possível afirmar que a política oficial destinada aos povos indígenas foi a da aculturação.

A Constituição Federal de 1988 "[...] não repetiu o dispositivo que constou em todas as constituições republicanas (com exceção da Constituição de 1937), que dispunha a incorporação dos indígenas à comunhão nacional." (LEIVAS; RIOS; SCHÄFER, 2014, p. 377). Mais do que isso: passou a reconhecer no art. 231 o direito à diferença e a titularidade permanente de direitos coletivos e, no art. 232, a superação da tutela, ao reconhecer-Ihes a legitimidade processual para atuar em nome próprio.

Mas o destaque maior certamente foi o reconhecimento de territorialidade própria, através da garantia do direito originário e imprescritivel sobre as terras tradicionalmente ocupadas, a posse permanente, o usufruto exclusivo dos recursos nelas existentes e o dever da União em demarcá-las, tudo previsto nos parágrafos do art. 231. Embora já houvesse previsão da demarcação desde a Constituição de 1934, a de 1988 inaugurou tratamento diferenciado do tema, afastando-se das políticas tutelares e integracionistas.

A transição de paradigma também é observada no sistema universal dos direitos humanos, sobretudo pela substituição da Convenção no 107 da OIT, de 1957, pela Convenção nº 169 Sobre Povos Indígenas e Tribais em Países Independentes, de 1989, que avança significativamente no reconhecimento cultural, no direito à autodeterminação, à consulta prévia, à territorialidade, a novas formas de participação e, inclusive, à autodeclaração como critério fundamental de pertencimento aos grupos por ela protegidos (OIT, 1989).

Neste ciclo constitucional, a forma tradicional de ocupação espacial dos povos indígenas e também das comunidades tradicionais não pode ser analisada através da noção moderna e capitalista de apropriação do espaço como propriedade privada. Para se compreender como os povos indígenas se apropriam do território e nele se organizam, é preciso se desprender de categorias de representação territorial eurocêntricas.

Em termos gerais, o território é considerado como condição para a reprodução da vida, mas não no sentido de um bem material ou fator de produção. Território "[...] é o conjunto de seres, espíritos, bens, valores, conhecimentos, tradiçōes que garantem a possibilidade e o sentido da vida individual e coletiva." (LUCIANO, 2006, p. 101). Por este motivo, alerta Gersem Luciano (2006) que "A territorialidade indígena não tem nada a ver com soberania política, jurídica e militar sobre um espaço territorial, como existe em um Estado soberano. Tem a ver com um espaço socionatural necessário para se viver individual e coletivamente" (LUCIANO, 2006, p.103).

Além disso, políticas territoriais conduzidas pelo Estado desde o período colonial são cruciais para a definição das demandas atuais dos povos in- 
dígenas por território. Séculos de políticas de escravidão, catequização e aculturação significaram na dimensão territorial a expulsão dos índios de seus territórios. Como consequência, diversos grupos étnicos foram forçados a migrar e se dispersar para sobreviver, modificando muitos aspectos de sua vida social. Essa reorganização social forçada é definida por Pacheco de Oliveira (1998) como "processos de territorialização", e implicam:

1) a criação de uma nova unidade sociocultural mediante o estabelecimento de uma identidade étnica diferenciadora; 2) a constituição de mecanismos políticos especializados; 3) a redefinição do controle social sobre os recursos ambientais; 4) a reelaboração da cultura e da relação com 0 passado (PACHECO DE OLIVEIRA, 1999, p. 54-55).

Estes são os elementos a serem considerados na interpretação dos direitos territoriais indígenas, o que parece conflitar de maneira bastante concreta com a ideia de "marco temporal da ocupação" e da sua fundamentação pelo Supremo Tribunal Federal.

\section{0 caso da Terra Indígena Raposa Serra do Sol e o marco temporal da ocupação}

Após décadas de impasse sobre a demarcação da Terra Indígena Raposa Serra do Sol, em 2008 o STF iniciou a apreciação do mérito da questão no julgamento histórico, a partir de ação popular PET 3388 proposta por senadores de Roraima em 20 de abril de 2005 perante o Supremo Tribunal Federal, suscitando a nulidade da Portaria $\mathrm{n}^{\circ}$ 534/2005 do Ministério da Justiça e do Decreto Presidencial de homologação que demarcaram a Terra Indígena Raposa Serra do Sol. A área de 1,747 milhão de hectares possui atualmente uma população de 23.119 pessoas, entre a etnias Ingarikó, Macuxi, Patamona, Taurepang e Wapichana.

Além das questões jurídicas, o caso demonstrou a complexidade das disputas de terras entre ín- dios e nāo-índios, que ocorrem desde o período colonial. Ao chegar no STF e provocar a interpretação das normas constitucionais indígenas com profundidade inédita, o julgamento pode ser considerado um verdadeiro leading case sobre direitos territoriais dos povos indígenas (MOTA; GALAFASSI, 2009, p. 76).

Diante dos muitos temas abordados na decisão, certamente os mais polêmicos dizem respeito às salvaguardas institucionais e ao denominado "conteúdo positivo do ato de demarcação das terras indígenas", presente no corpo do texto, ao qual se inclui a afirmação de que a data da promulgação da Constituição Federal, 5 de outubro de 1988, seria o marco temporal insubstituível para a verificação da ocupação tradicional indígena.

O Min. Ricardo Lewandowski afirmou que a data representaria uma espécie de "fotografia" do momento, enquanto que o relator, Min. Carlos Ayres Britto, chamou-a de "chapa radiográfica" da situação de ocupação. Assim, a teoria do indigenato, há décadas seguida pelo STF como paradigma do reconhecimento dos direitos originários indígenas, parecia estar sendo relativizada para a adoção de uma "teoria do fato indígena". Desta forma sustentou o Min. Carlos Ayres Britto:

I - o marco temporal da ocupação. Aqui, é preciso ver que a nossa Lei Maior trabalhou com data certa: a data da promulgação dela própria (5 de outubro de 1988) como insubstituível referencial para o reconhecimento, aos índios, "dos direitos sobre as terras que tradicionalmente ocupam". Terras que tradicionalmente ocupam, atente-se, e não aquelas que venham a ocupar. Tampouco as terras já ocupadas em outras épocas, mas sem continuidade suficiente para alcançar o marco objetivo do dia 5 de outubro de 1988. Marco objetivo que reflete o decidido propósito constitucional de colocar uma pá de cal nas intermináveis discussões sobre qualquer outra referência temporal de ocupação de área indígena. Mesmo que essa referência estivesse grafada em Constituição anterior. É exprimir: a data de verificação do fato em si da ocupação fundiária é o dia 5 de outubro de 1988, e nenhum outro. Com o que se evita, a 
um só tempo: a) a fraude da subitânea proliferação de aldeias, inclusive mediante o recrutamento de índios de outras regiões do Brasil, quando não de outros países vizinhos, sob o único propósito de artificializar a expansão dos lindes da demarcação; b) a violência da expulsão de índios para descaracterizar a tradicionalidade da posse das suas terras, à data da vigente Constituição. Numa palavra, o entrar em vigor da nova Lei Fundamental Brasileira é a chapa radiográfica da questão indígena nesse delicado tema da ocupação das terras a demarcar pela União para a posse permanente e usufruto exclusivo dessa ou daquela etnia aborígine. Exclusivo uso e fruição (usufruto é isso, conforme Pontes de Miranda) quanto às "riquezas do solo, dos rios e dos lagos" existentes na área objeto de precisa demarcação (§ 2 do art. 231), devido a que "os recursos minerais, inclusive os do subsolo", já fazem parte de uma outra categoria de "bens da União" (inciso IX do art. 20 da CF); (BRASIL, 2010, p. 137-138).

Apesar de tal entendimento, a tradicionalidade não poderia ser afastada pela verificação "cartesiana" da presença indígena. O próprio STF afirmou que injustiças históricas não seriam avalizadas, porque a ausência física em 5 de outubro de 1988 poderia ser suprida pela comprovação de expulsão das terras:

A tradicionalidade da posse nativa, no entanto, não se perde onde, ao tempo da promulgação da Lei Maior de 1988, a reocupação apenas não ocorreu por efeito de renitente esbulho por parte de não-índios. Caso das "fazendas" situadas na Terra Indígena Raposa Serra do Sol, cuja ocupação não arrefeceu nos índios sua capacidade de resistência e de afirmação da sua peculiar presença em todo o complexo geográfico da "Raposa Serra do Sol" (...) o que termina por fazer desse tipo tradicional de posse um heterodoxo instituto de Direito Constitucional, e não uma ortodoxa figura de Direito Civil. (BRASIL, 2010, p. 77).

Porém, quais açōes podem ser consideradas "renitentes" para descaracterizar o marco temporal em um contexto de tutela, como era antes de 1988? Neste sentido, tanto a constitucionalidade do marco temporal quanto a interpretação de seus pressupostos é questionada, sobretudo porque $2^{\underline{a}}$ Turma do STF vem aplicando-a para fundamentar anulaçōes de terras indígenas, embora não houvesse força vinculante no caso Raposa.

O primeiro caso é da Terra Indígena Guyraroká, no Município de Caarapó, Mato Grosso do Sul, território e 11 mil hectares declarado em 2009 para posse de 525 Guaranis Kaiowá, cuja anulação ocorreu em 2014. Após, em 2015, veio a anulação da Terra Indígena Limão Verde, de 1.335 índios Terena, localizada no Município de Aquidauana, também no Mato Grosso do Sul. Para além da (in)constitucionalidade, as particularidades dos casos ensejam a análise da colonialidade presente na tese e na sua fundamentação.

\section{Colonialidade do marco temporal na atual jurisprudência do STF}

\subsection{Marco temporal e a colonialidade do ser}

O desenvolvimento da dimensão do ser na colonialidade se deu em função da necessidade de considerar a experiência vivida dos sujeitos coloniais e a produção e reprodução de sua sub-alteridade pelo discurso colonial, ainda presente no constitucionalismo pluriétnico pós-88. Assim, a suspeita permanente sobre a humanidade dos índios (e dos negros) transforma-se, na modernidade, no questionamento da sua racionalidade. Deste processo, resulta a construção da diferença sub-ontológica - legitimada e formalizada pela ideia de raça - e a imposição de verdadeiro "inferno diário" na experiência vivida dos sujeitos colonizados (MALDONADO-TORRES, 2007, p. 154).

Tais ideias são reforçadas pelo discurso colonial que, segundo Bhabha (2007), visa a construir o sujeito colonizado como um tipo degenerado sobre a base de origem racial, de modo a justificar a conquista e os sistemas de administração, seja dos próprios corpos ou dos seus territórios (BHABHA, 2007, p. 95-96). 
Estas ideias são encontradas na forma como a tese do marco temporal vem sendo fundamentada e, sobretudo, aplicada pelo STF nos casos de anulação de terras indígenas (TI Guyraroká e TI Limão Verde), nos seguintes pontos: a) a persistência da tutela, com a não participação das comunidades indígenas nos processos que visam a anulação de suas terras demarcadas; b) o consequente bloqueio da possibilidade de resistência, por conta da inferiorização da tutela; c) a anti-historicidade da tese, ao desconsiderar a história recente de violência, tutela e tomada de territórios tradicionais, sobretudo na ditadura civil-militar, que influencia a subjetividade indígena atual e sua capacidade de resistência; d) o agravamento dos conflitos atuais, das mortes $e$ das condições de vida precárias, com a revisão de direitos e de demarcações em estágio avançado ou mesmo concluídas.

Em relação ao retorno de elementos de tutela, o caso da TI Limão Verde, dos índios Terena do Município de Aquidauana/MS, é emblemático neste sentido. Após manifestação do STF pela aplicação do marco temporal, a comunidade indígena dos Terena solicitou seu ingresso de forma incidental no processo, na qualidade de litisconsorte passivo necessário, a fim de contestar a versão dos Ministros de que não houvera ocupação e resistência ao esbulho e, assim, requerer a nulidade do julgamento. Em 27 de abril de 2015, o pedido foi indeferido pelo Min. Teori Zavascki, nestes termos:

[...] a Comunidade Terena não logrou êxito em demonstrar qualquer prejuízo decorrente de sua não participação no processo, sendo certo que (a) integrou o polo passivo da demanda a FUNAI - órgão a quem cabe 'a defesa judicial ou extrajudicial dos direitos dos silvícolas e das comunidades indígenas' (art. 35 da Lei 6.001/73) - e (b) a causa foi acompanhada em todas as instâncias pelo Ministério Público Federal'. É de salientar que ambos os órgãos interpuseram recursos em favor da Comunidade Terena. (BRASIL, 2015c, p. 2).
No caso da anulação da TI Guyraroká, ocupada por 500 Guaranis-Kaiowá no município de Caarapó/MS, também ocorreu por meio de revisão de conjunto probatório por via inadequada e pela negativa de participação no processo da comunidade indígena diretamente afetada, apesar do pedido formal da própria comunidade, que constituiu advogado e identificou suas lideranças. Em sede de Embargos Declaratórios, o Ministro Gilmar Mendes também rejeitou a participação da comunidade indígena no processo:

Em relação à representação da Comunidade indígena Guyraroká, ressalto que a FUNAl é órgão federal do Estado brasileiro responsável pela proteção dos índios e de seus bens, ao qual cabem todos os estudos e levantamentos que precedem a demarcação, nos termos do art. 231 da Constituição Federal, bem como da Lei 5371, de 5.12.1967. Em petição, essa própria Fundação reafirma que "0 resgate dos direitos legítimos e tradicionais dos Kaiowá de Guyraroka" é sua obrigação jurídica e administrativa, por ser o órgão do governo federal instituído para executar sua política indigenista. (fl. 262). Inclusive, porque, "entre suas atribuiçōes, está o 'exercício dos poderes de representação ou assistência jurídica inerentes ao regime tutelar do índio', nos termos do art. $1^{\circ}$, parágrafo único da Lei 5371/67". Afasto, portanto, o argumento da Comunidade indígena Guyraroká a indicar que sua não participação teria impedido sua defesa, especialmente em relação à demonstração do período de ocupação das terras em questão. (BRASIL, 2015c, p. 11).

O advento do art. 232 da Constituição de 1988, que assegura a participação em nome próprio dos indivíduos e comunidades indígenas nos processos judiciais que thes dizem respeito, significou a superação do regime tutelar e da incapacidade relativa que perdurou durante o paradigma integracionista. Ainda que o MPF e a FUNAI tenham dentre suas atribuições o acompanhamento dos processos judiciais das comunidades indígenas, por conta da qualidade da parte, não podem fa- 
lar em substituição aos índios, sobretudo quando os mesmos manifestam formalmente o desejo de participar das açōes, como de fato ocorreu por diversas vezes nos processos citados.

Antes de 1988, justamente pela política tutelar, as comunidades indígenas não tinham acesso por si próprias ao Sistema de Justiça, e não possuíam mecanismos efetivos de comunicação com o poder público para reivindicar os territórios tomados pelo avanço do agronegócio e pelos processos de colonização. Além disso, são inúmeros os relatos de violência e expulsões cometidas pelos próprios órgãos indigenistas, SPI e posteriormente a FUNAl, intensificados no século XX com a ditadura militar de 1964.

Neste sentido, o Relatório da Comissão Nacional da Verdade, publicado em 2015, traz fartos relatos que comprovam a relação entre as violaçōes de direitos humanos e os interesses econômicos de não-índios e do próprio Estado brasileiro sobre os territórios indígenas. A espoliação das terras indígenas pelo Estado e a consequente invasão de não-índios foi uma prática recorrente a partir dos anos 1930, sobretudo no Estado do Mato Grosso do Sul².

Mais atual, o Relatório da Violência Contra os Povos Indígenas, divulgado pelo Conselho Indigenista Missionário no ano de 2016, também apresenta relatos e dados de formas de violência direta e indireta contra indígenas, como assassinatos de lideranças, mortalidade na infância, omissão e morosidade na regularização das terras, desatenção à saúde, racismo e abuso de poder. Como nos anos anteriores, chama atenção a perversa realidade enfrentada pelos indígenas do Mato Grosso do Sul, especialmente os GuaraniKaiowá, Guarani-N̄andeva e Terena, contra os quais foram registrados 10 ocorrências de ata- ques a aldeias, 20 assassinatos, 3 casos de violência sexual, 45 suicídios e taxa de mortalidade infantil duas vezes maior que a média nacional (CIMI, 2016).

\subsection{Marco temporal e a colonialidade do saber}

Com as narrativas intra-europeias da modernidade, universalizou-se uma experiência local como se fosse o modelo natural e homogêneo de sociedade a ser seguido por todos os povos do mundo. Tal fenômeno, o eurocentrismo, relegou essas experiências plurais ao outro lado da linha abissal do conhecimento hegemônico, encobrindo e classificando as cosmologias indígenas como mero "folclore" e "mitologia".

Neste sentido, a problemática levantada pela fundamentação do marco temporal e do renitente esbulho pelo STF, em relação à colonialidade do saber, tem como ideia central a desconsideração das cosmologias e territorialidades indígenas que fundamentam o seu ser e estar no mundo, promovendo a violação do direito à diferença.

Disto decorre uma série de consequências: a) a invalidação das formas tradicionais indígenas de relação com o território e com o Estado, tornando-as sem efeito para o direito, a despeito do art. 231 da Constituição; b) equiparação da posse tradicional à posse civil, principalmente ao se exigir controvérsia possessória judicializada como forma de resistência, além de toda a nomenclatura civilista dos conceitos forjados; c) a não consideração das normas e jurisprudência internacional de proteção e promoção dos direitos dos povos indígenas como fonte primária de decisão no direito interno; e d) a ausência de diálogo concreto com a antropologia, bem como o uso conveniente das informaçōes dos laudos antropológicos,

\footnotetext{
${ }^{2}$ A Comissāo Nacional da Verdade (CNV), criada pela Lei no 12.528, de 2011, e instituída em 16 de maio de 2012, entregou em dezembro de 2014 seu relatório final à sociedade identificando as violaçōes de direitos humanos cometidas por agentes do Estado no período de 1946 a 1988 . No volume II do relatório, foram incluídos os povos indígenas nas discussōes oficiais da Justiça de Transiçāo, ao se constatar as diversas violaçōes sofridas por muitas etnias neste período: esbulhos, extermínio, mortes causadas por grandes obras, contágio por doenças infecto-contagiosas, prisōes, torturas e maus tratos. Pelo menos 8.350 indígenas foram mortos no período. (BRASIL, 2014c, p. 204-205).
} 
desconsiderando passagens que narram formas de resistência.

Considerando a relação peculiar que os indígenas desenvolvem com o território, expressada pelas diversas territorialidades e processos de territorialização, a avaliação da ocupação tradicional e de eventual resistência à expulsão não pode ser feita pelos mesmos conceitos do paradigma cultural dominante, mas a partir da sua organização social, costumes e tradiçōes, como determina o artigo 231 da Constituição Federal. Ocorre que a fundamentação da tese do marco temporal pelo STF incorre nesta espécie de "epistemicídio" (SANTOS, 2009).

Logo após o julgamento da PET 3.388 em 2009, e após o trânsito em julgado com os Embargos Declaratórios de 2012, no qual o relator reiterou a ausência de força vinculante, muitas análises preliminares destacaram a ressalva de que a ideia de renitente esbulho impedia a perda da tradicionalidade da ocupação pela aplicação do marco temporal. Entretanto, na anulação da Tl Limão Verde, o STF entendeu por restringir em muito a compreensão sobre o que poderia ser considerado resistência para descaracterização do marco temporal. Nas palavras do relator, Min. Teori Zavascki:

Também não pode servir como comprovação de "esbulho renitente" a sustentação desenvolvida no voto vista proferido no julgamento do acórdão recorrido, no sentido de que os índios Terena pleitearam junto a órgãos públicos, desde o começo do Século XX, a demarcação das terras do chamado Limão Verde, nas quais se inclui a Fazenda Santa Bárbara. Destacou-se, nesse propósito, (a) a missiva enviada em 1966 ao Serviço de Proteção ao Índio; (b) o requerimento apresentado em 1970 por um vereador Terena à Câmara Municipal, cuja aprovação foi comunicada ao Presidente da Funai, através de ofício, naquele mesmo ano; e (c) cartas enviadas em 1982 e 1984, pelo Cacique Amâncio Gabriel, à Presidência da Funai. Essas manifestaçōes formais, esparsas ao longo de várias décadas, podem representar um anseio de uma futura de- marcação ou de ocupação da área; não, porém, a existência de uma efetiva situação de esbulho possessório atual. (BRASIL, 2015, p. 15).

Deste modo, consolidou-se a ideia de que a resistência dos indígenas à expulsão comprovada de suas terras somente é válida se representar, de preferência, uma demanda possessória judicializada, nos moldes do conhecimento hegemônico e excludente do Estado-nação e do direito monista. De nada vale a ação silenciosa de permanência, o apelo aos órgãos indigenistas tutelares e a resistência física de enfrentamento, sobretudo em um período de políticas oficiais de integracionismo e de atrocidades cometidas pelos agentes de Estado na ditadura civil-militar.

Esta interpretação do STF sobre o esbulho denuncia a problemática de confundir institutos totalmente diferentes: a ocupação tradicional, baseada na territorialidade indígena e reconhecida como direito originário pela Constituição, e a posse do direito civil, questão de fato recuperada por controvérsia possessória judicializada.

Duprat (2006) demonstra que essa impropriedade conceitual vem prejudicando conflitos fundiários entre índios e não-índios desde muito antes da tese do renitente esbulho:

\begin{abstract}
Uma ação vocacionada à tutela de direito de cunho nitidamente civilista neutraliza a disciplina constitucional dos territórios indígenas, porque a luta processual se desenvolve sob controle das normas constitutivas daquele campo e valendo-se apenas das armas nele autorizadas. Assim, elementos tais como posse velha, ocupação física, passam a ser acriticamente definitórios de direitos possessórios. (DUPRAT, 2006, p. 172).
\end{abstract}

Igualando-se as temáticas, as concepçōes cosmológicas de território das etnias indígenas não são consideradas, somente a definição oficial de posse. Ignora-se que a permanência dos índios nas terras das quais foram desalojados, mesmo como trabalhadores rurais, pode ser uma manifestação possível de ocupação tradicional, pois assim 
mantêm a proximidade com os locais sagrados e a esperança de retorno futuro.

São estes os elementos da fundamentação do marco temporal e do renitente esbulho que manifestam a colonialidade do saber, promovendo hierarquias entre as formas de compreensão do território e a formação de sociabilidades. A consequência para o direito é a interpretação dos direitos territoriais indígenas ainda de forma marcadamente civilista e hegemônica, olvidando que o paradigma pluriétnico da Constituição de 1988 inclui a consideração de outras cosmologias e territorialidades.

\subsection{Marco temporal e a colonialidade do poder}

A colonialidade do poder pode ser definida como uma matriz de poder global originada na conquista da América a partir da introdução da ideia de raça como fundamental para o controle dos âmbitos básicos da existência social. A partir desta dimensão subjetiva da matriz de poder, alia-se uma dimensão material, expressada por um sistema de controle do trabalho surgido a partir de novas relaçōes materiais de produção, que utilizou da mão-de-obra escrava para a acumulação primária em nível mundial, sendo determinante para expansão do capitalismo. A conjugação destas dimensōes, de forma inédita, é legitimada pela imposição do conhecimento eurocêntri$\mathrm{co}$, encobrindo saberes locais (colonialidade do saber) e (re)produzindo o "Outro" como sujeito degenerado, através do discurso colonial (colonialidade do ser).

Deste modo, a ideia do marco temporal pode se articular com a colonialidade do poder a partir de algumas reflexões: a) inclusão do marco temporal na Proposta de Emenda Constitucional (PEC) no 215/2000, no parecer da Advocacia-Geral da União (AGU) e os atores políticos com interesse na consolidação desta tese; e b) a genealogia das relaçōes fundiárias e de poder e a relação com os territórios indígenas.
A partir do que já foi discutido, não seria impróprio afirmar que não há consenso de que a Constituição de 1988 seja o marco temporal dos direitos territoriais indígenas, menos ainda de que direitos originários devam ter um marco temporal objetivo para a sua garantia. De qualquer forma, a brecha aberta para se anular terras demarcadas e para se dificultar a demarcaçāo de novas terras indígenas foi abraçada por setores da sociedade e da classe política do país.

Exemplo concreto é a Proposta de Emenda Constitucional (PEC) no 215, de 2000, iniciativa do Deputado Federal Almir Sá (PPB-RR) que objetiva transferir a competência da demarcação de terras indígenas - mas também de territórios quilombolas e de unidades de conservação da natureza - do Poder Executivo Federal para o Congresso Nacional.

Em parecer do relator da Comissão Especial instaurada, o Dep. Federal Osmar Serraglio (PMDBPR) votou pela aprovação da PEC e de outras apensadas, na forma de um substitutivo proposto ao final do ano de 2015. Neste substitutivo, o Deputado propôs a inclusão do marco temporal no art. 231, como característica definidora das terras indígenas e como requisito obrigatório de verificação pelo laudo antropológico.

Diante disto, torna-se necessário historicizar os conceitos e ideias jurídicas que buscam respostas simples a questōes complexas. Muitos territórios indígenas foram considerados como terras devolutas e outorgadas pelos Estados a particulares por conta do art. 64 da Constituição de 1891. O próprio órgão indigenista criado em 1910, o SPI, certificou a inexistência de índios em algumas localidades, para que então os Estados incorporassem ao seu patrimônio e emitissem títulos de propriedade a particulares (SOUZA FILHO, 2012, p. 133).

Esta foi uma foi uma estratégia comum dos processos de colonização do interior do país, com vistas a expandir as fronteiras agrícolas e promover o desenvolvimento, já que, no imaginário po- 
sitivista, os índios deveriam ser assimilados como trabalhadores rurais ou urbanos. Observa Souza Filho (2012) que as terras "deixadas" pelos índios foram juridicamente nomeadas como "aldeamentos extintos" e transferidas ao domínio do Estado ou da Uniāo (SOUZA FILHO, 2012, p. 135).

Portanto, as terras indígenas demarcadas ou retomadas dos anos 90 em diante possuem este passado em comum, assim como a cadeia dominial das propriedades rurais particulares em disputa. Neste sentido, ainda que o art. 67 do Ato das Disposiçōes Constitucionais Transitórias tenha assegurado que a União concluiria a demarcação das terras indígenas até 1993, a realidade é que os conflitos somente se agravaram.

Veja-se que o quadro atual de demarcação de terras no Brasil reserva ao Mato Grosso do Sul uma situação de confinamento territorial das comunidades indígenas em áreas muito diminutas, revelando as consequências das relaçōes de colonização do passado. São 54 terras indígenas neste estado, entre os vários estágios jurídicos do processo demarcatório. O Instituto Socioambiental produziu um relatório em 2015 no qual há um panorama específico dos Guarani no Estado do Mato Grosso do Sul:

Em Mato Grosso do Sul, existem 37 Terras Indígenas ocupadas pelos Guarani Kaiowa e Guarani N̄andeva, que representam, em área, menos de 0,5\% da área total do estado. Boa parte dessas terras está em processo de reconhecimento (16), mas mesmo as homologadas ou reservadas - um total de 21 terras - encontram-se invadidas por fazendeiros ou têm seus processos de demarcação contestados e até anulados na Justiça. É o caso, entre muitas outras, da TI ArroioKora (Paranhos/MS), homologada em 2009, mas disputada por fazendeiros e parcialmente suspensa pela Justiça - agravando a situação de violência permanente contra a comunidade. (ISA, 2015b, p. 10).

Mesmo neste contexto, iniciativas como o marco temporal contemplam atores do sistema político brasileiro. O Congresso Nacional possui atuando o que se convencionou chamar de "bancada ruralista": Deputados Federais, Senadores e outros políticos, de diferentes partidos e regiōes do país, ligados ao agronegócio e a grandes latifúndios, que atuam em benefícios particulares de sua classe e contra os interesses das populaçōes tradicionais e do meio ambiente.

O espaço oficial da bancada é representado pela legítima Frente Parlamentar da Agropecuária (FPA), entidade associativa de Deputados e Senadores registrada no Congresso a cada legislatura. A FPA conta com Estatuto próprio e, atualmente, possui 198 Deputados Federais e 21 Senadores como membros.

De fato, integram a FPA políticos de diversos partidos e não necessariamente proprietários de terras ou com discursos públicos contrários aos direitos das comunidades tradicionais e ao meio ambiente, porquanto as frentes parlamentares são espaços legítimos da política nacional e o desenvolvimento da agricultura e da pecuária são temas de interesse público inconteste. Entretanto, os posicionamentos públicos da FPA são de apoio explícito à PEC nํ 215 e a outras medidas que significam retrocessos aos direitos indígenas ${ }^{3}$.

E isto não apenas no Legislativo: mais recentemente, em 20 de julho de 2017, a AGU voltou a relacionar as condicionantes do caso Raposa e o marco temporal à atuação dos servidores federais nos processos de demarcação, desta vez através de um "parecer vinculante" (em 2012, foi

\footnotetext{
${ }^{3}$ Membros da Bancada Ruralista também são responsáveis por instaurar em 2015 a Comissão Parlamentar de Inquérito (CPI) para investigar a conduta da Fundação Nacional do Índio (FUNAI) e do Instituto Nacional de Colonização e Reforma Agrária (INCRA) acerca dos procedimentos de demarcação e de titulaçāo de territórios tradicionais. A CPI foi presidida pelo Deputado Alceu Moreira (PMDB/RS) e relatada pelo Deputado Nilson Leitāo (PSDB/MT), que ocupa o cargo de presidente da FPA. Terminou por produzir relatório questionando os processos administrativos de demarcação e indiciando 67 pessoas por supostos crimes, incluindo lideranças indígenas, ativistas e profissionais ligados institucionalmente às questōes indígenas, como antropólogos e Procuradores da República (BRASIL, 2017).
} 
o Ministério da Justiça que editou uma Portaria com mesmo conteúdo, que logo foi atacada e suspensa). O Parecer no 0001/2017/GAB/CGU/ AGU foi assinado pelo Presidente da República e publicado no Diário Oficial da União, o que indica a posição atual do Governo Federal sobre direitos territoriais indígenas.

Portanto, é significativa a vinculação entre a classe política e o latifúndio brasileiro. Esta correlação de forças desigual faz com que as comunidades indígenas fiquem suscetíveis a perda de território, mas também às violências do campo, à mortalidade infantil e a altas taxas de suicídio. Além disso, o debate sobre o avanço de medidas juridicamente complexas como a PEC 215 resta bloqueado pelo lobby político.

Sendo assim, a tese do marco temporal, da forma como é construída e fundamentada, parece contribuir para a manutenção de tal realidade de concentração fundiária por elites agrárias, com origens que remontam ao período colonial, e com relaçōes de poder que se estendem ao Congresso As incursōes pela tomada de territórios indígenas, aliadas às ideias assimilacionistas que confinaram os índios em reservas e os colocaram como mão-de-obra barata do agronegócio em expansão, reproduziram a classificação social baseada na ideia de raça de que fala Quijano (1992) como origem da colonialidade do poder. Além disso, perceber que tais correlaçōes de força persistem atualmente, reforça a análise de que a colonialidade do poder estruturou as sociedades latino-americanas mesmo após os processos de independência e, mais recentemente, os processos de redemocratização.

\section{Conclusão}

A posição que vem sendo firmada pelo STF em sua jurisprudência, para além de significar uma possível inconstitucionalidade, também vai na contramão do direito internacional dos direitos humanos e das mais recentes interpretaçōes sobre a territorialidade dos povos indígenas, que buscam afirmar o direito com base no reconhecimento da plurietnicidade, da autodeterminação e da consciência dos processos históricos que marcaram a relação entre Estado, sociedade e povos indígenas.

Conclui-se que o estabelecimento de um limitador temporal aos direitos originários dos povos indígenas denota o bloqueio e a invisibilização das cosmologias indígenas e do passado de tutela, esbulho e violência estatal, contribuindo para a perpetuação de conflitos fundiários violentos e da situação de vida precária dessas populações.

Assim, a colonialidade do ser se expressa no bloqueio da resistência dos povos indígenas, na desconsideração da história recente de violência e na perpetuação do discurso colonial que constrói e reproduz o "outro" como hierarquicamente inferior. A colonialidade do saber se manifesta, sobretudo, pela imposição de um discurso civilista que neutraliza um direito constitucional, cujo fundamento está na consideração de outros saberes e cosmologias, bem como territorialidades e temporalidades. Por fim, a colonialidade do poder é reforçada pelas correlaçōes de poder e de submissão dos povos indígenas que o marco temporal contribui para legitimar, em vez de buscar evitar ou, ainda, transformar.

A crítica descolonial e a historicização de conceitos jurídicos construídos a partir de uma longa narrativa eurocentrada e hegemônica oferece outro nível de compreensão do que está em jogo, uma vez que ultrapassa a simples hermenêutica constitucional. Além disso, tal compreensão oferece ferramentas mais sólidas para a contestação e a litigância contrária a ideias com o marco temporal da ocupação.

\section{Referências}

BHABHA, H.K. 2007. El lugar de la cultura. Buenos Aires, Manantial, 308 p.

BRASIL Supremo Tribunal Federal. Petição 3.388 - RR, Relator: Ministro Carlos Ayres Britto. Brasília, DF, 19 de março de 2009. Diário da Justiça Eletrônico. 01 jul. 2010. 
BRASIL. 2014. Relatório: textos temáticos. Volume II. Comissão Nacional da Verdade. Brasília, CNV, 402 p.

BRASIL Supremo Tribunal Federal. Embargos Declaratórios no Recurso Ordinário em Mandado de Segurança no 29.087 - DF. Relator: Ministro Gilmar Mendes. Brasília, DF, 20 de outubro de 2015. Diário da Justiça Eletrônico. 13 nov. 2015.

BRASIL 2017. Câmara dos Deputados. Relatório Final da Comissão Parlamentar de Inquérito FUNAI-INCRA 2 - Criada por meio do Requerimento de Instituição de CPI no 026/2016. Disponível em: http://www.camara.leg.br/internet/ comissoes/comissoes-especiais/CPI/RELAT\%C3\%93RIO\%20 CPI\%20FUNAIIINCRA\%202.pdf; Acesso em: 25.07.2017.

CONSELHO INDIGENISTA MISSIONÁRIO. 2016. Relatório Violência contra os Povos Indígenas no Brasil: dados de 2015. Brasília, CIMI, 171 p.

DUPRAT, D. 2006. Demarcaçāo de terras indígenas: o papel do Judiciário. In: RICARDO, B.; RICARDO, F. (ed.), Povos indígenas no Brasil: 2001-2005. São Paulo, Instituto Socioambiental, p. 172-175.

DUSSEL, E. 1998. Ética de la liberación en la edad de la globalización y de la exclusión. Madrid, Editorial Trotta, 661 p.

DUSSEL, E. 2000. Europa, modernidad y eurocentrismo. In: LANDER, E. (org.), La colonialidad del saber: eurocentrismo y ciencias sociales. Perspectivas latinoamericanas. Buenos Aires, CLACSO, p. 41-53.

GALLOIS, D.T. 2004. Terras ocupadas? Territórios? Territorialidades? In: RICARDO, F. (org.), Terras Indígenas e Unidades de Conservação da natureza: o desafio das sobreposiçōes. São Paulo, Instituto Socioambiental, p. 37-41.

GROSFOGUEL, R. 2009. Para descolonizar os estudos de economia política e os estudos pós-coloniais: transmodernidade, pensamento de fronteira e colonialidade global. In: SANTOS, B.S.; MENESES, M.P. (Orgs.), Epistemologias do sul. Coimbra, CES, p. 383-417.

INSTITUTO SOCIOAMBIENTAL. 2015. Impactos da PEC 215/2000 sobre os povos indígenas, populaçōes tradicionais e o meio ambiente. Brasília, ISA, 52 p.

LEIVAS, P.G.C.; RIOS, R.R.; SCHÄFER, G. 2014. Educação escolar indígena no direito brasileiro: do paradigma integracionista ao paradigma do direito a uma educação diferenciada. Revista da AJURIS, Porto Alegre, v. 41, n. 136, p, 371-383.

LUCIANO, G.S. 2006. O índio brasileiro: o que você precisa saber sobre os povos indígenas no Brasil hoje. Brasília, LACED/Museu Nacional, 224 p.

MALDONADO-TORRES, N. 2007. Sobre la colonialidad del ser: contribuciones al desarrollo de un concepto. In: CASTRO-GÓMEZ, S.; GROSFOGUEL, R. (orgs.), El giro decolonial: reflexiones para una diversidad epistémica más allá del capitalismo global. Bogotá, Siglo del Hombre Editores, p. 127-167.

MIGNOLO, W.D. 2008. La opción descolonial. Revista Letral, Granada, n. 1, p. 4-22.

MIGNOLO, W.D. 2010. Desobediencia Epistémica: Retórica de la Modernidad, Lógica de la Colonialidad y Gramática de la Descolonialidad. Buenos Aires, Ediciones del Signo, 126 p.

MOTA, C:; GALAFASSI, B. 2009. A demarcação da Terra Indígena Raposa Serra do Sol: processo administrativo e conflitos judiciais. In: MIRAS, J.T. [et. al], Makunaima grita: Terra Indígena Raposa Serra do Sol e os direitos constitucionais no Brasil. Rio de Janeiro, Beco do Azougue, p. 73-125.

PACHECO DE OLIVEIRA, J. 1998. Uma etnologia dos "indios misturados"? Situação colonial, territorialização e fluxos culturais. Mana, Rio de Janeiro, vol. 4, n. 1, p. 47-77.

PACHECO DE OLIVEIRA, J. 1999. Ensaios em Antropologia Histórica. Rio de Janeiro, Editora UFRJ, 272 p.

QUIJANO, A. 1992. Colonialidad y modernidad/racionalidad. In: BONILLA, H. (Org.), Los conquistados: 1492 y la población indígena de las Américas. Ecuador, Libri Mundi, Tercer Mundo Editores.

QUINTERO, P. 2010. Notas sobre la teoría de la colonialidad del poder y la estructuración de la sociedad en América Latina. Papeles de Trabajo - Centro de Estudios Interdisciplinarios en Etnolingüística y Antropología Socio-Cultural, Rosário, n. 19: 1-15.

SANTOS, B.S. 2009. Para além do pensamento abissal: das linhas globais a uma ecologia de saberes. In: SANTOS, B.S.; MENESES, M.P. (Orgs.), Epistemologias do sul. Coimbra, CES, p. 23-71.

SOUZA FILHO, C.F.M. 2012. O renascer dos povos indígenas para o direito. $1^{\underline{a}}$ ed. $8^{\underline{a}}$ reimp., Curitiba, Juruá, 212 p.

\section{Dailor Sartori Junior}

Mestre em Direito, com ênfase em Direitos Humanos, pelo Centro Universitário Ritter dos Reis (bolsa CAPES). Bacharel em Direito pela Universidade Federal do Rio Grande do Sul. Especialista em Ética e Educação em Direitos Humanos pela Universidade Federal do Rio Grande do Sul. 